\title{
Chapter 11 \\ Climate Change Resiliency Through Mangrove Conservation: The Case of Alitas Farmers of Infanta, Philippines
}

\author{
Dixon T. Gevaña, Josephine E. Garcia, Clarissa D. Ruzol, \\ Felisa L. Malabayabas, Liezl B. Grefalda, Elizabeth O'Brien, Elsa P. Santos, \\ and Leni D. Camacho
}

\begin{abstract}
Transformation, transition, and paradigm shift are increasingly applied concepts in literature on climate resiliency to describe changes in society and the environment. Here, we considered mangroves to be dynamic socio-ecological systems, subject to increasing anthropogenic pressures that present complex challenges for the design of effective coastal governance. Analysing these systems through a participatory approach, we consulted a community who lives in close relationship with mangroves, the Alitas farmers of Infanta, Quezon Province, Philippines. This community has improved decision-making processes for the development of adaptation strategies to climate change. In turn, a sustainably managed and conserved mangrove forest promotes human well-being and resilience, particularly for those households whose livelihoods are dependent on the resources that mangroves provide. This paper examined the importance of mangrove land management that addresses climate change hazards. We synthesised various perspectives on the importance of mangrove conservation for enhancing climate resiliency by: (1) describing the climate-related hazards that affect local communities and mangroves; (2) describing socio-institutional structures influencing effective mangrove conservation and local resilience; and (3) identifying climate change adaptation strategies that promote local development and mangrove conservation. This paper establishes a collaborative management framework for future risk-resilience management that operates alongside coastal communities within the Philippines and across the global stage.
\end{abstract}

D. T. Gevaña $(\bowtie)$ J. E. Garcia · C. D. Ruzol · F. L. Malabayabas · L. B. Grefalda · E. P. Santos ·

L. D. Camacho

Department of Social Forestry and Forest Governance, College of Forestry and Natural

Resources, University of the Philippines Los Baños, Los Baños, Laguna, Philippines

e-mail: dtgevana@up.edu.ph

E. O'Brien

Department of Ecology and Evolutionary Biology, University of Michigan, Ann Arbor, MI, USA 
Keywords Adaptation - Climate change - Coastal - Collaborative management · Mangroves $\cdot$ Rehabilitation $\cdot$ Resilience $\cdot$ Stakeholders $\cdot$ Transformative change

\subsection{Introduction}

Promoting climate risk-resilient coastal communities requires effective anticipation of climate change impacts on the integrity of socio-ecological systems. There is now an increasing need to develop participatory approaches to coastal resilience assessment to improve local understanding of risk and resilience, provide capacitybuilding benefits, and create platforms for knowledge and experience sharing (Frankenberger et al. 2013; Pfefferbaum et al. 2014; Sharifi and Yamagata 2016). Such assessments are most effectively done by gathering knowledge from a wide range of stakeholders. Designing guidelines on how coastal communities can manage and sustainably use mangrove resources constitutes an important step towards mitigating the potential impacts of climate change.

A participatory approach to coastal resilience assessment is vital in decisionmaking on trade-offs, as well as fostering local ownership and legitimacy. Such steps are aimed at enhancing the impacts of development services on rural areas through more resilient ecosystems and adaptable communities. By prioritising ecosystem and community resiliency in rural coastal communities, vulnerabilities can be reduced, both over the long and short terms (Renaud et al. 2013). A participatory approach also supports the National Convergence Initiative (Republic of the Philippines, Department of Agrarian Reform), which integrates people, their economy, and the environment, particularly through landscape and seascape approaches.

The concept of resilience has received widespread attention in the field of disaster risk management (DRM) since the release of the "Hyogo Framework for Action 2005-2015: Building the resilience of nations and communities to disasters" by the United Nations International Strategy for Disaster Reduction (UNISDR 2007). This concept is most commonly expressed as the capacity of a society to 'bounce back', or to cope, withstand, resist and recover rapidly from the impacts of hazardous events (IPCC 2012; Ostadtaghizadeh et al. 2015; Turnbull et al. 2013). In the field of climate change, resilience is defined as the ability of a system, community or society exposed to hazards to resist, absorb, accommodate to and recover from the effects of a hazard in a timely and efficient manner (UNISDR 2007).

Resilient coastal communities take deliberate action to reduce risks from coastal hazards with the goal of avoiding disaster and accelerating recovery in the event of a disaster. They adapt to changes based on experience and the applying of lessons learned. Enhancing a coastal community's resilience requires integrating and maintaining an optimal balance of three community-based frameworks, typically viewed as independent and separate domains: community development, coastal management, and disaster management (Fig. 11.1). Community development provides the enabling governance, as well as the socioeconomic and cultural conditions for resilience (Center for Community Enterprise 2000). Coastal management 


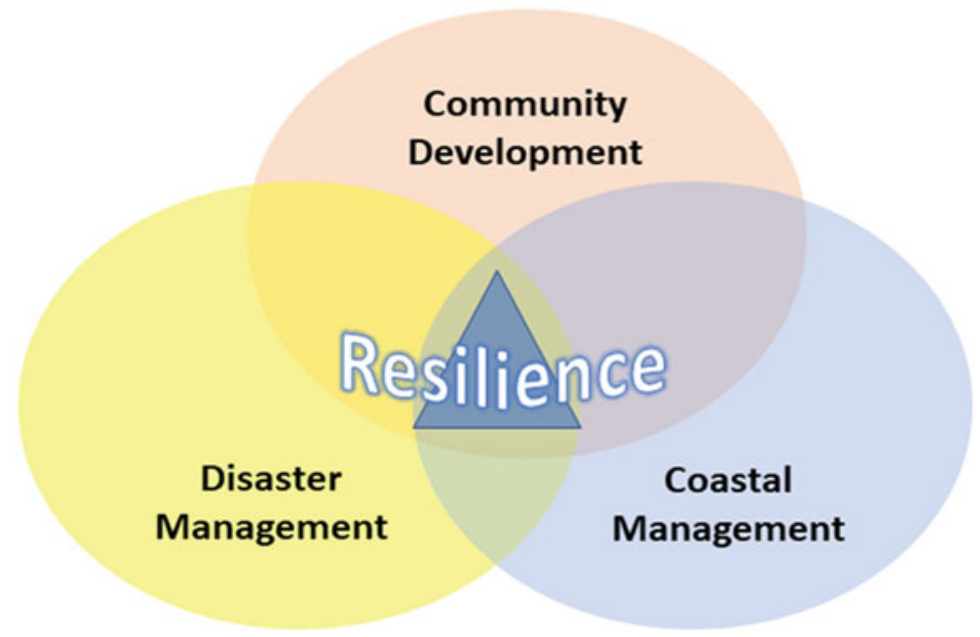

Fig. 11.1 Resilience as an integrating framework for community development, coastal management, and disaster management domains (Source: US Indian Ocean Tsunami Warning System Program 2007)

provides the framework for managing human use of coastal resources, including mangroves and the coastal zone, in order to maintain environmental and ecosystem resilience (Chua 1998; White et al. 2005). Lastly, disaster management focuses on preparedness, response, recovery and mitigation to reduce human and structural losses from disaster events (Abarquez and Murshed 2004).

Mangrove forests are vital tropical coastal ecosystems that promote resilience. Globally, they offer numerous services that improve the lives of the communities they border (Garcia et al. 2014; Gevaña et al. 2018; Renaud et al. 2013). Mangroves are assemblages of tropical salt-tolerant or halophytic plants that grow between land and sea. Across the Philippines, they have aided in coastal protection during storm surges (Garcia et al. 2014), contributed to local economies (Menéndez et al. 2019), supported marine biodiversity (Honda et al. 2013), and mitigated climate change through carbon sequestration (Camacho et al. 2011; Gevaña and Im 2016; Gevaña et al. 2019). Combined, these services represent the resiliency of the mangrove ecosystem. This ecosystem resiliency can in turn support community resiliency, and vice versa.

Promoting local resilience necessitates an in-depth look at the socio-ecological dimensions of both local communities and mangroves. These dimensions include: local knowledge and appreciation of the socio-ecological production systems of mangroves; commitment to forest conservation; concrete policies, plans and programmes on disaster risk management and climate change adaptation; institutional capacity to enforce and implement these; and mechanisms for equitable sharing of responsibilities and benefits among stakeholders. Pal et al. (2019) further underscores the importance of identifying and nurturing local initiatives that create 
transformative socio-ecological changes. These transformative changes should be examined in terms of:

- Enabling environment: political will; evidence and research/information; and awareness and capacities.

- Transformational domains: policies and governance, innovation; and social and behavioural change.

- Characteristics of transformation: inclusive development; systemic solutions; catalytic action; ability for scale-up; and sustainability (Mustelin and Handmer 2013).

It is important to emphasise the implementation of participatory approaches in the development and implementation of coastal resilience assessment because of their multiple benefits. According to Sharifi (2016), emphasis should be given to promotion of participatory approaches in all stages of assessment. A number of studies have noted a mix of participatory approaches, such as focus group discussions (FGDs), social mapping, Venn diagrams, resource mapping, institutional relations through mapping, or climate hazards mapping to incorporate local communities' lessons learned and knowledge in results (Akter 2015; Ali et al. 2018; Mallick 2013; Moles et al. 2014; Sameen 2018).

The objective of this paper is to underscore the vital role of multi-stakeholder participation in comprehensive planning and implementation towards strengthening coastal community resiliency. A case study was carried out in Barangay Alitas, Infanta, Quezon, a rural coastal community that is remotely located away from centres of commerce and vulnerable to various climate variabilities. The primary objective of this study was to elicit perspectives on the importance of mangrove conservation for enhancing resilience to climate change hazards. It involved: (1) description of major climatic hazards and events that have affected the local community; (2) analysis of the importance, influence and interests of various mangrove stakeholders; (3) description of major socio-ecological production systems; (4) examination of the local government's institutional capacity to uplift the community's climate resilience; and (5) discussion on the importance of collaborative mangrove management in promoting socio-ecological sustainability.

\subsection{Methodology}

\subsubsection{Description of the Study Area}

Alitas is an estuarine barangay ${ }^{1}$ in the municipality of Infanta in the province of Quezon (Fig. 11.2). It is situated at approximately $14^{\circ} 42^{\prime} 19.44^{\prime \prime} \mathrm{N}, 121^{\circ} 40^{\prime} 25.32^{\prime \prime}$ $\mathrm{E}$ on the island of Luzon, with a total area of 676 hectares (Fig. 11.2 and Table 11.1).

\footnotetext{
${ }^{1} \mathrm{~A}$ barangay is a local community that is recognised as the smallest political unit in the Philippines.
} 


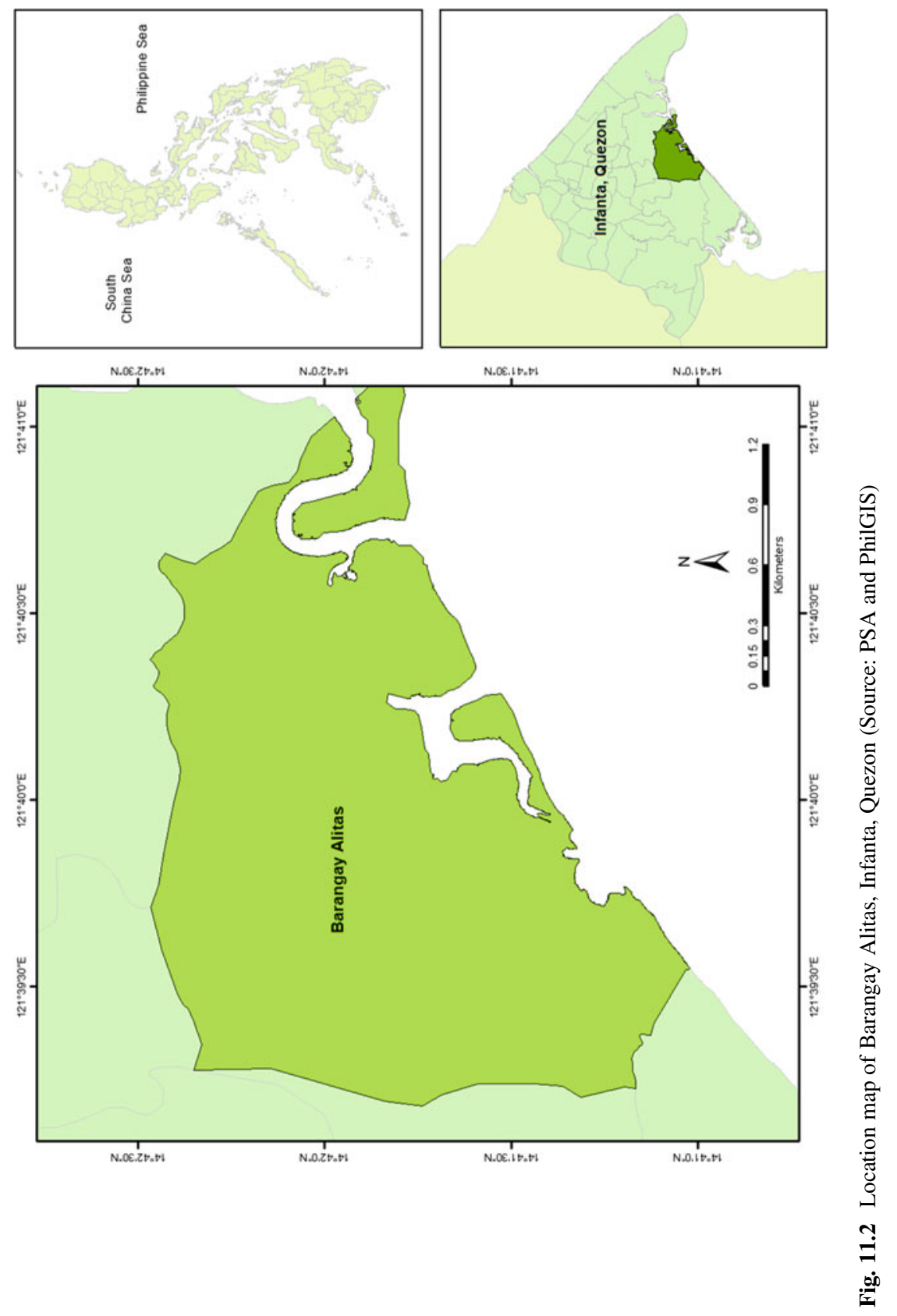


Table 11.1 Basic information of the study area

\begin{tabular}{l|l}
\hline Country & Philippines \\
\hline Province & Quezon \\
\hline District & 1 st district \\
\hline Municipality & Infanta \\
\hline Size of geographical area (hectare) & 34,276 \\
\hline Number of indirect beneficiaries & 69,079 \\
\hline Dominant ethnicity(ies), if appropriate & Tagalog \\
\hline Size of case study/project area (hectare) & Alitas community (676) \\
\hline Number of direct beneficiaries & 1124 \\
\hline Dominant ethnicity in the project area & Tagalog \\
\hline Geographic coordinates (latitude, longitude) & $14^{\circ} 42^{\prime} 19.44^{\prime \prime} \mathrm{N} ; 121^{\circ} 40^{\prime} 25.32^{\prime \prime} \mathrm{E}$ \\
\hline
\end{tabular}

Its population in 2017 was 1324, which made them one of the less populated barangays of Infanta (PSA 2018). The annual population growth rate stands at $0.85 \%$. At this rate, the population is expected to double in 30 years, putting pressure on forestlands and coastal resources via demand for more areas for cultivation, resource extraction, or settlement. Agriculture and fisheries are the common forms of livelihood. Agricultural lands are private areas, while fishery grounds are the mangroves which are of limited access to surrounding communities. The people of Alitas have to rely on multiple sources of income to counter the effects of storms (at least 20 storms pass through the town of Infanta every year), monsoon rains, and the trade winds. It is common to find farmers who engage in fishing or collecting fishery resources in mangroves, wine production, trading, and labour services, sequentially or simultaneously, as the season permits. Some farmers are members of the Alitas Farmers Association (AFA), which was organised in 2008. This people's organisation serves as a partner to government in the management of mangroves and nipa palm (Nypa fruticans) plantations. This organisation is popular locally for its production of nipa wine, known as lambanog. Mangrove cover in Alitas is estimated to be around 355 ha (Fig. 11.3), an area which the AFA has helped restore.

\subsubsection{Data Collection}

A participatory research approach was adopted for collecting essential sociodemographic, institutional and biophysical information. Data collection activities were conducted from January to mid-March 2020 and involved the active participation of local stakeholders, particularly AFA members, in conducting field data collection activities. The following activities were conducted:

- Project orientation on the importance of mangrove ecosystems and concept of climate change

This initial step involved identification and research coordination with local stakeholders, which included local communities, government institutions (local 

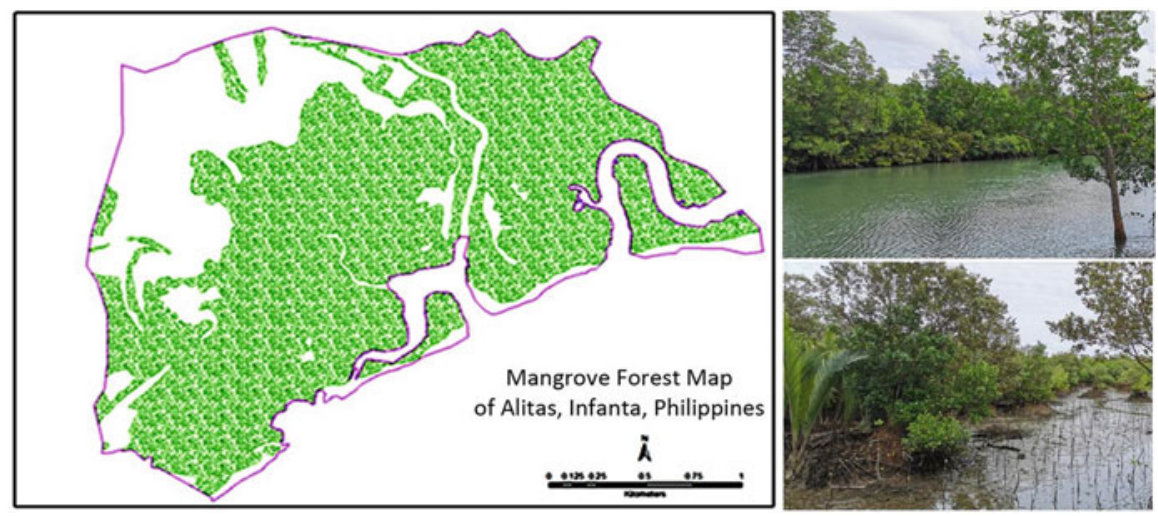

Fig. 11.3 Mangrove forest of Alitas, Infanta, Quezon, Philippines (Source: PSA and PhilGIS; Credit: DT Gevaña and JE Garcia)

government units, or LGUs; and the Department of Environment and Natural Resources or DENR), and other relevant stakeholders of the mangrove forests.

- Collection and analysis of secondary data

Secondary information on the study site's bio-physical, socio-demographic, and institutional conditions was collected from various sources including barangay and municipal-level LGUs and DENR.

- Stakeholder analysis

Analysis was conducted through focus group discussions that involved representatives from relevant government agencies and selected members of AFA. These included: (1) an LGU group with six participants; (2) an AFA-member group with ten participants; and (3) a non-AFA-member group with six participants. In addition, key informant interviews with five selected government officials and an AFA officer were also performed to enrich the information obtained from FGDs. Key informant interviews focused on the capacity of stakeholders to carry out adaptation responses, as well as assessment of perceptions on how mangroves are being managed.

- Resource and climate hazard mapping

This involved mapping of natural resources in the community, as well as identification of areas where impacts of climate variability have been observed. The latest satellite images were printed to illustrate the physical condition of the site. Participants were asked to locate: (1) mangrove areas, (2) settlements, and (3) climatic hazards that affected the local community.

- Institutional capacity analysis

This analysis was done through key informant interviews with municipal-level LGU staff (particularly offices on agriculture, environment, local planning and development, disaster risk reduction and management, and social work). A questionnaire was utilised for the interviews, covering seven criteria for evaluating institutional capacity, namely: access rights and entitlements; decisionmaking processes; information flows; application of new knowledge; capacity 
to anticipate risk; capacity to respond; and capacity to recover and change. Each criterion was evaluated using a Likert scoring scale: (1) very poor; (2) poor; (3) moderate; (4) good; and (5) very good.

\subsection{Key Findings}

\subsubsection{Climatic Threats}

The Alitas community endures numerous natural disasters every year, such as typhoons and tropical storms. A typhoon is a tropical cyclone that has a maximum wind speed of 118-220 kilometres per hour (kph) while a tropical storm is a tropical cyclone with a maximum wind speed of 62-117 kph. Between 2005 and the time of this study, a total of 21 typhoons and 16 tropical storms visited Alitas.

As recalled by the respondents, the community experienced the following events: Tropical Depression Winnie (2004); Typhoon Tisoy (2019); and a tornado (buhawi) (1995) (see Table 11.1). Among these, Tropical Depression Winnie was mentioned as the most destructive. The respondents' recall was very vivid as they shared during the focus group discussions (FGDs) what their life was like during that time. The severity of impacts to locals prompted them to use a rarely used term delubyo (a Filipino word for a large flood disaster), to refer to the continuous pouring of rain that caused flash floods and submerged the entire Municipality of Infanta. Fortunately, only 20 houses were flooded, but the water easily subsided. There was no recollection among respondents of significant negative impacts of Typhoon Tisoy. Lastly, only a few locals experienced the tornado, or buhawi, (1995) that lasted for an hour and left four houses with damaged roofs.

Along with disasters come risks. As explained by CAPRA (2012), it is certain that the occurrence of a natural, technological, or natural/societal event on a highly vulnerable population will result in human, infrastructure, economic, or financial loss. Risk comprises several elements: primary hazards, exposed elements, and the vulnerability of the community to the event (e.g. poorly-built housing, riverbank construction, and lack of social safety nets). CAPRA is a probabilistic risk assessment platform that aims to strengthen the institutional capacity for assessing, understanding and communicating disaster risk, with the ultimate goal of integrating disaster risk information into development policies and programs.

The risk events experienced by the community made an impact on agriculture and mangroves. Respondents were asked about the degree or extent of the impacts of the risk events (Table 11.2). For Tropical Depression Winnie that resulted in flooding, the FGD participants gave a score of 2 (affected) and explained how agriculture, mangroves, and the environment were affected. Rice fields were greatly damaged by floods and erosion, and mangrove vegetation was removed. Some facilities in the community were also not spared, resulting in a month-long blackout, and potable water supply was lost because several wells were filled with mud. Only those who lived along the river were spared from lack of potable water. Tornado damage was 
Table 11.2 Perceived impacts of risk events in Alitas

\begin{tabular}{|c|c|c|c|c|}
\hline Risk event & History & Likelihood & Impacts & $\begin{array}{l}\text { Degree of } \\
\text { impacts } \\
(1-\text { not } \\
\text { affected } \\
2- \\
\text { affected } \\
3- \\
\text { extremely } \\
\text { affected })\end{array}$ \\
\hline $\begin{array}{l}\text { Buhawi } \\
\text { (Tornado) }\end{array}$ & 1995 & Once & $\begin{array}{l}\text { Only four houses affected—roofs } \\
\text { destroyed }\end{array}$ & 1 \\
\hline $\begin{array}{l}\text { Tropical } \\
\text { depression, } \\
\text { delubyo type }\end{array}$ & $\begin{array}{l}\text { Winnie } \\
\text { (29 Nov. to } \\
3 \text { Dec. 2004) }\end{array}$ & $\begin{array}{l}\text { First time } \\
\text { to } \\
\text { experience }\end{array}$ & $\begin{array}{l}\text { Agriculture } \\
\text { - Rice fields filled with mud and crops } \\
\text { severely damaged } \\
\text { Mangrove } \\
\text { - Mangrove trees stripped of branches } \\
\text { - Some fishes in aquaculture ponds } \\
\text { died due to heavy siltation } \\
\text { Facilities } \\
\text { - Blackout for a month for the entire } \\
\text { municipality } \\
\text { - Houses along the river damaged } \\
\text { - No potable water because a number } \\
\text { of wells became silted with mud }\end{array}$ & 2 \\
\hline Typhoon & $\begin{array}{l}\text { Tisoy (Dec } \\
\text { 2019) }\end{array}$ & Often & $\begin{array}{l}\text { Not affected } \\
\text { Barangay Alitas has irrigation canals } \\
\text { that helped drain flood from other } \\
\text { barangays. With the presence of } \\
\text { mangroves and nipa, storm surge } \\
\text { impact was also lessened. }\end{array}$ & 2 \\
\hline
\end{tabular}

generally rated as 1 (not affected), owing to the mangroves which provided wind breaks.

\subsubsection{Mangrove Stakeholders}

The direct users of mangrove resources are the local farmers and fisherfolk, particularly AFA members. AFA has 95 members, the majority of which are women (66). One of the programmes of AFA is a mangrove rehabilitation project. This programme was started in 2009 and aimed at reverting abandoned fishponds back to mangroves. In 2013, AFA's efforts were awarded, recognised as a best practice by the Philippine government's National Greening Program. Today, AFA maintains and monitors the mangrove rehabilitation site and plans to expand their rehabilitation efforts to remaining abandoned fishponds. 


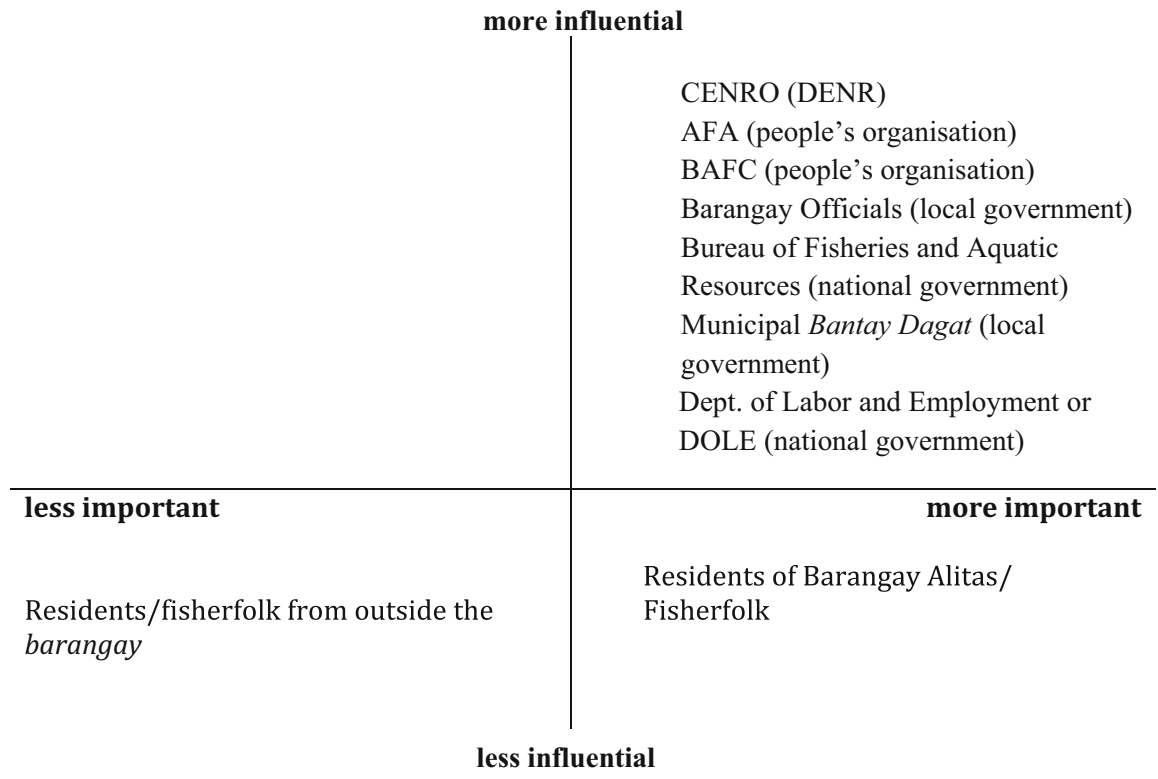

Fig. 11.4 The degree of importance and influence of mangrove stakeholders as perceived by AFA members

The DENR, through its local office called the Community Environment and Natural Resources Office (CENRO), is also an important government institution that assists AFA in its mangrove conservation work. CENRO provides funds for mangrove rehabilitation by local communities and tenure arrangement through the Community Based Forest Management Agreement (CBFMA) programme. This stewardship agreement programme provides AFA with 25 years of stewardship rights (renewable for another 25 years) to utilise and conserve mangroves.

Municipal and barangay LGUs also assist AFA and CENRO in mangrove management. The barangay, or community-level LGU, provides the needed ordinances for coastal protection. Together with the municipal-level LGU, it also deputises Bantay Dagat, or sea wardens, to protect coastal areas from illegal fishing and timber poaching activities.

Another organisation that influences the management of the mangrove ecosystem is the Barangay Agriculture and Fisheries Council (BAFC). This council is comprised mainly of rice farmers who may or may not be members of AFA. During its meetings in the barangay, the farmer members are reminded of the need to protect mangroves for their ecosystem services.

The different user groups and mediating institutions in Alitas are arranged in Figs. 11.4 and 11.5. The diagrams show their relative importance and influence as perceived by members and non-members of AFA, respectively. In these matrices, "importance" refers to the stake of the interest group. The more important the stake is, the more it needs to be considered in policy and management. On the other hand, 


\begin{tabular}{|c|c|}
\hline \multicolumn{2}{|c|}{ more influential } \\
\hline & CENRO (DENR) \\
\hline & AFA (people's organisation) \\
\hline & BAFC (people's organisation) \\
\hline & Barangay Chair (local government) \\
\hline & Residents of Barangay Alitas \\
\hline less important & more important \\
\hline Residents/fisherfolk from outside the & Farmers \\
\hline barangay & Fisherfolk \\
\hline & $\begin{array}{l}\text { Municipal Bantay Dagat (local } \\
\text { government) }\end{array}$ \\
\hline \multicolumn{2}{|c|}{ less influential } \\
\hline
\end{tabular}

Fig. 11.5 The degree of importance and influence of mangrove stakeholders as perceived by non-AFA members (Credit: Gevaña et al. 2019)

"influence" refers to the capacity to create an impact or influence decisions. For instance, the more influential the interest group is, the more it could cause change in policy and management.

Results showed that there are varying interests and roles involved in mangrove resources and their management. Both AFA members and non-members consider CENRO, BAFC, AFA, and barangay LGU officials as highly influential stakeholders with important interests in mangrove rehabilitation as well. Mediating institutions such as the CENRO and the municipal-level LGU were viewed to have vital roles in assisting AFA in conserving mangroves. Both groups (AFA members, and non-members) noted that the interests of the people from outside Alitas concerning the mangrove ecosystem are less important than the rest of the stakeholders. They are also described as less influential in mangrove management.

Overall, mangrove conservation appears as the most common interest and goal among major stakeholders. This implies that forest rehabilitation and protection activities serve as platforms for collaboration among stakeholders.

\subsubsection{Socio-Ecological Production System Promoting Local Community Resilience}

According to UNU-IAS, Biodiversity International, IGES, and UNDP (2014), resilient socio-ecological production landscapes and seascapes (SEPLS) can be defined as robust systems that demonstrate a balance in the use of natural resources and protection of biodiversity in promoting human well-being. This concept adheres to the three socio-ecological tenets of: (1) consolidation of wisdom on securing diverse ecosystem services; (2) integration of traditional and ecological knowledge with scientific knowledge; and (3) adoption of collaborative management. The 

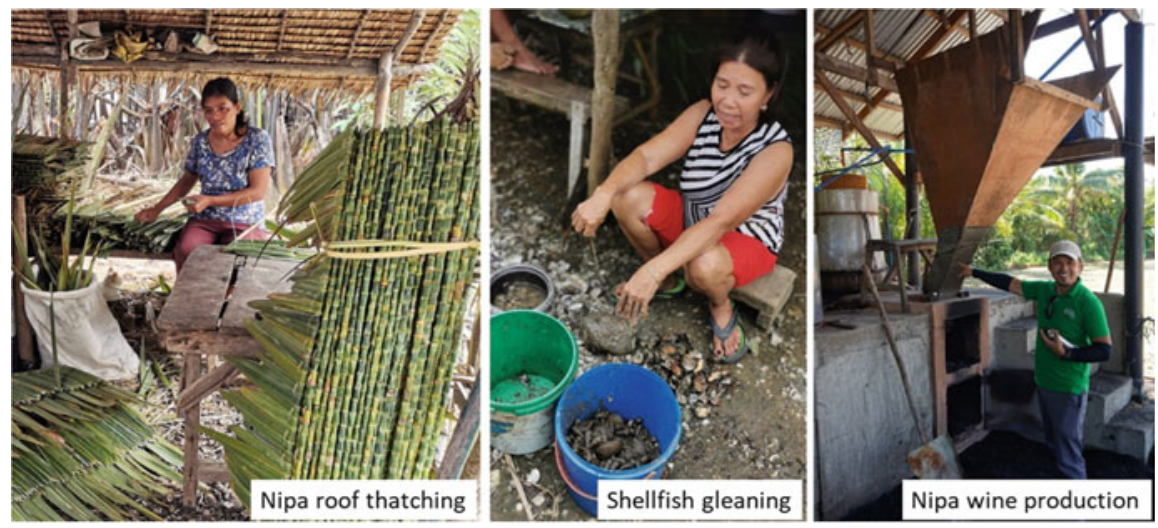

Fig. 11.6 Mangrove-dependent livelihoods of Alitas community (Credit: DT Gevaña and E O’Brien)

resilience of the SEPLS in Alitas is best exemplified by the local livelihoods that mangrove conservation supports, local knowledge, and stakeholders' commitment to work together in protecting mangroves. Community resilience is commensurate of the mangrove areas that are well-kept.

Rehabilitation and protection of mangroves (locally termed pakatan) and nipa zones (locally termed nipahan) are collective goals aimed at keeping the community adaptive to climate hazards. Different user groups benefit from the rehabilitated and protected mangrove areas either directly or indirectly. The direct user groups of the pakatan are the residents of Barangay Alitas (Fig. 11.6). The fisherfolks benefit directly from three main types of marine resources extracted from the mangrove ecosystem: fish, shrimp and shellfish. Aside from fishing, other livelihoods include production of lambanog (nipa wine) and nipa shingles, sold as roofing material. There are three lambanog distilleries owned by AFA, and many other privately operated distilleries located in Alitas, where residents process nipa into lambanog.

AFA members also obtain additional income from joining mangrove rehabilitation projects of the DENR (Fig. 11.7). They provide labour in nursery production, field planting, and site maintenance activities (e.g. replanting and brushing). Women dominate in nursery seedling production activities, while men are engaged more in field planting and plantation maintenance.

Local residents regard the pakatan to be essential in protecting them from typhoons, strong winds, and monsoon rains, serving as a buffer zone that minimises the risk of flooding. Residents also collect fallen branches and driftwood called daghip from the pakatan to use as fuelwood and fence material for their plant nurseries. Daghip are trunks or branches of trees damaged by strong winds that drift ashore. Figure 11.8 shows a map of land use and climatic hazards that was generated through participatory mapping.

Tapok-concrete houses serving as evacuation areas for vulnerable families during strong typhoons 


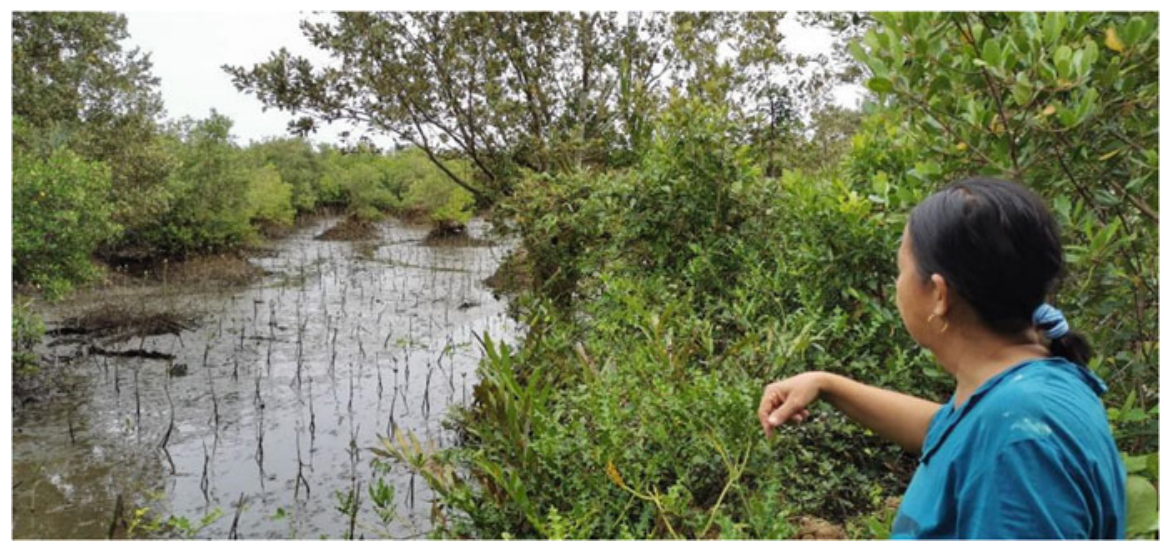

Fig. 11.7 Mangrove rehabilitation project as an additional local income source (Credit: DT Gevaña)

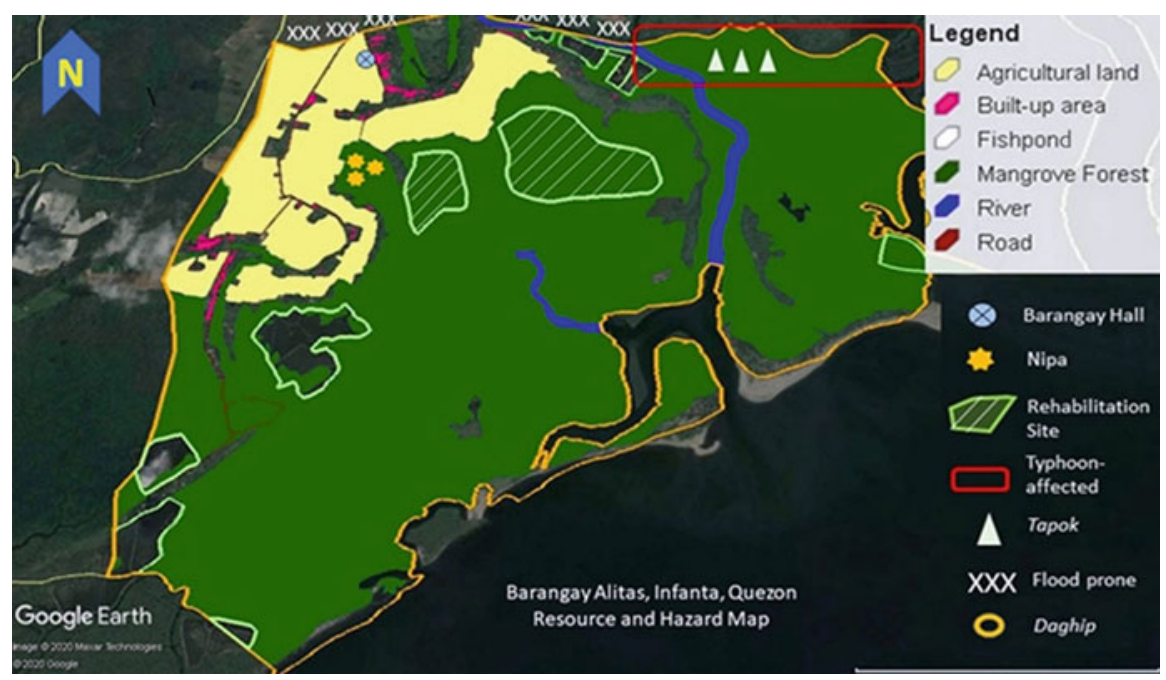

Fig. 11.8 Community resource and hazard map of Alitas community (Source: Google Earth ver. 1.2.2019; Credit: JE Garcia)

Daghip — driftwood and damaged branches collected as fuelwood and fence material for nurseries

The mangrove ecosystem contributes to local resiliency. People living within it and those from nearby barangay can freely fish or glean for shellfish in mangrove areas for food and income. Local people also have high regard for the important role of mangroves in providing nursery grounds for marine fishes, particularly the tulingan (tuna), which is a major product of the town. Every year, the whole town of Infanta celebrates the Tulingan Festival to commemorate abundant blessings from 
the sea and mangroves. Further, policies prohibiting the cutting of mangroves and the use of destructive fishing methods such as salambaw (poisoning) and lumpot (use of fine nets with less than $3 \mathrm{~cm}$ diameter mesh) are strictly enforced.

Local resilience is also reflective of effective local climate change adaptation strategies that rest on maintaining healthy mangrove cover. During strong typhoons, some residents evacuate to saguban, a temporary shelter made of nipa that is located inside the nipa plantation and mangroves.

\subsubsection{Institutional Capacity}

Table 11.3 summarises findings on the institutional capacity of the municipal-level LGU to promote local resilience and the sustainable management of mangroves. In terms of application of new knowledge in addressing climatic hazards and conserving mangrove resources, the key informant interview respondents regarded the LGU's capacity to be 'very good', with a mean score of 4.8. The level of awareness and knowledge on climate change and the mangrove ecosystem of Alitas was also observed to be very good.

In view of access rights and entitlements, including the human, physical and financial resources of the LGU, respondents indicated that the agency has good capacity, with a score 4.0. For human resources, plans and programmes exist to increase the number of staff (with permanent positions and ample trainings) to ensure that the LGU's mandates for enhancing resiliency and protecting the environment are well implemented. In terms of financial resources, respondents underscored a certain degree of need to improve fund allocation for disaster management and mangrove management. Further, sourcing of funds from private institutions was mentioned as a good strategy to address budget deficits.

Decision-making processes for disaster management and mangrove conservation were described to be generally effective. Respondents noted that there are concrete and clear protocols (on administrative, legislative and executive mandates) that guide offices and staff to develop and implement programmes. Further, the conduct of regular meetings was also regarded as helpful in ensuring timely and coordinated

Table 11.3 Summary of scores on the institutional capacity of LGU-Infanta for climate-related risk management

\begin{tabular}{l|c|l}
\hline Institutional capacity/resilience indicators & Median & Description of institutional capacity \\
\hline Access rights and entitlements & 4.0 & Good \\
\hline Decision-making processes & 4.0 & Good \\
\hline Information flow & 3.5 & Moderate to good \\
\hline Application of new knowledge & 4.8 & Good to very good \\
\hline Capacity to anticipate risk & 4.5 & Good to very good \\
\hline Capacity to respond & 4.0 & Good \\
\hline Capacity to recover and change & 4.0 & Good \\
\hline
\end{tabular}


completion of tasks and targets. With all the protocols in place, flexibility to change decisions or correct actions (as needs arise) was, however, identified as an area needing improvement.

The LGU's institutional capacity to anticipate risk (4.5), capacity to respond to risk (4.0), and capacity to recover and change during disasters (4.5) were all perceived to be 'good'. This capacity is evident in the strict observance of protocols on disaster risk management, as mandated by national law and monitored by the national government.

In terms of information flow, which is defined to as how effectively other stakeholders (such as the local community of Alitas and private organisations) can easily access accurate information from the LGU about risk management and climate change adaptation, respondents found the LGU's capacity to be 'moderate'. Improving the LGU's capacity in data management information systems was mentioned as necessary to be able to package and communicate plans and programmes on disaster and forest management to local communities and the broader public. Furthermore, skills in processing essential data (e.g. meteorological information and geo-hazards maps) must be improved in order to formulate correct and updated plans.

\subsubsection{Collaborative Mangrove Conservation Promoting Local Resilience}

Figure 11.9 provides a conceptual framework and synthesis of the perceived importance of conserving mangroves in promoting local development, also depicting how climate resilience can be enhanced through improvement of the government's institutional capacity. This framework also underscores collaborative management among major stakeholders to encourage: (1) local commitment and participation in mangrove protection; and (2) capacity improvement of different institutions in climate and disaster risk management. Lessons from the case of Alitas suggest

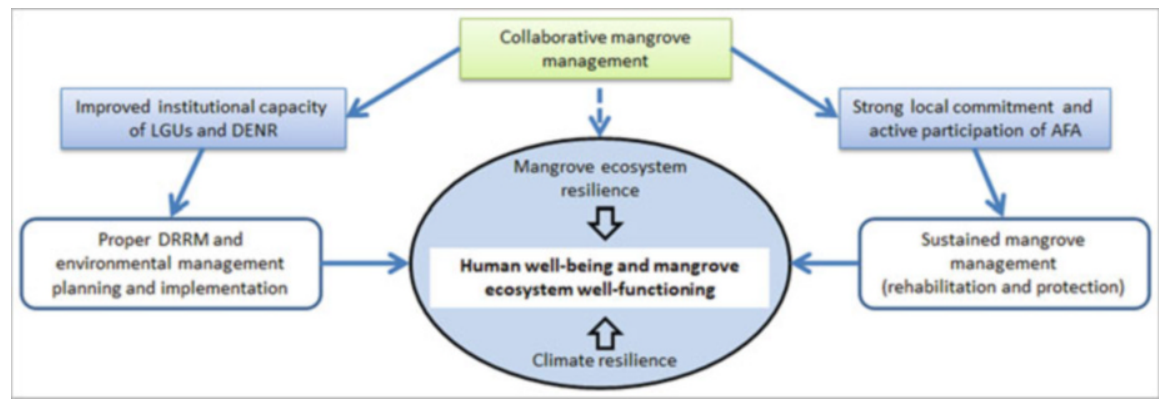

Fig. 11.9 Conceptual framework on how mangrove conservation promotes local resilience in Alitas (Credit: DT. Gevaña et al. 2019) 
how investing in mangrove conservation reverberates to achievement of well-being for humans and a well-functioning ecosystem.

Furthermore, the distinct link between mangrove conservation and enhanced local resilience depicts the real essence of socio-ecological production landscape and seascape (SEPLS) management. Mangroves were generally perceived as the hinge that links various ecosystems (within the landscape) upon which diverse livelihoods are very much dependent. By pursuing collaborative mangrove management, community development is also promoted as: (1) the local community develops a sense of ownership, organisation and responsibility over mangrove management; (2) women and marginalised sectors are empowered through participation in mangrove conservation activities; (3) government and non-government stakeholders take on responsibility to assist the local community in mangrove protection efforts, thereby satisfying their institutional goals as well; (4) mangrove programmes (particularly reforestation) serve as a conduit for creating jobs and local income sources; (5) well-kept mangrove forests sustain and protect natural resourcedependent local livelihoods (e.g. farming, fishing, and nipa wine production) from the injurious impacts of climate change; and (6) new livelihoods (e.g. ecotourism) are developed that promote self-reliance in funding and sustain mangrove conservation activities.

\subsection{Discussion: Implications for Transformative Change}

Pursuing collaborative mangrove management promotes socio-ecological wellbeing and the resilience of stakeholders, particularly the local community of Alitas. The community now needs to harness and nurture these seeds of transformative change. These include the following:

- Local stakeholders have learned to regard mangrove conservation as an effective climate change adaptation strategy. They noted that keeping a good mangrove cover will lessen their vulnerability to the impacts of typhoons and floods. Likewise, local residents understood well that mangroves provide diverse ecosystem services, and these can only be sustained if they are properly managed. Continuously sharing such knowledge and appreciation of the mangrove's value with broader stakeholders and generations to come is essential.

- Active local participation in rehabilitation projects. This was regarded to be beneficial in creating additional income sources for the local community. Likewise, the intimate involvement of local people, particularly the AFA members, has also strengthened their sense of stewardship and commitment towards protecting the mangroves they planted.

- Local government units and CENRO are committed to assisting the local community in mangrove conservation. Such commitment is expressed in terms of the provision of livelihood projects, environmental law enforcement, and policy improvements that complement the community's interest in conserving 
mangroves. This sense of constituent governance enhances the local people's trust and support for the government, while assuring the achievement of its mandates and goals to promote local development as well.

- CBFMA provides a legal and long-term platform for sustaining mangrove rehabilitation efforts by encouraging more stakeholder collaboration. This tenure programme provides clear guidelines on the rights, roles and responsibilities of the AFA to serve as stewards and a partner of the government in mangrove conservation. It also highlights that the centrality of mangrove management rests on them. This opens up opportunities for other stakeholders (particularly private institutions and NGOs) to partner with AFA in local development projects that benefit the local community and the mangroves they manage.

\subsection{Conclusion and Recommendations}

This paper looked at the importance of managing mangroves to address climate change hazards and promote the sustainability of a socio-ecological production landscape and seascape. It synthesised various perspectives on the importance of mangrove conservation for enhancing climate resiliency by: (1) describing the climate-related hazards that affect local communities and mangroves; (2) describing the socio-institutional structures influencing mangrove conservation and local resilience; and (3) identifying climate change adaptation strategies that promote local development and mangrove conservation.

Climatic hazards, as a result of tropical depression was identified to have the most severe negative impact on the local community. Keeping a good cover of mangrove was recognised as key for counteracting severe impacts. Furthermore, mangrove conservation was perceived to have sustained various local livelihoods such as nipa wine production, farming and fishing. Ensuring the continuous delivery of these protective and provisioning services necessitates socio-institutional transformations that are pegged on a collaborative management platform. Findings from stakeholder analysis and assessment of institutional capacities on disaster risk management yielded two important lessons. First, collaborative management can be realised by harmonising diverse stakeholders (in terms of their interests) to help the local community (particularly AFA) manage their mangroves well. Second, the centrality of promoting climate resiliency rests on the ability and willingness of various stakeholders to work together.

There are evident seeds of transformative change that need to be nurtured. First, local stakeholders regard mangrove conservation as an effective climate change adaptation strategy. Second, there is active local participation in rehabilitation projects. Local commitment to rehabilitation is sustained by the diverse benefits that the local community enjoys from engaging in it. Third, government stakeholders are committed to assisting the local community in mangrove conservation. Lastly, adoption of the CBFMA tenure programme can provide a legal and long-term 
platform for sustaining mangrove rehabilitation efforts by encouraging more stakeholder collaboration with AFA and DENR.

Overall, this study underscores collaborative management as a prerequisite for a sustainable SEPLS and climate resiliency in the mangrove landscape. The best practices shown herein and the seeds of transformative change that have stimulated multi-stakeholder mangrove conservation could provide some lessons which other CBFMA programmes in the country could replicate or learn from.

Acknowledgements This case study was made possible through the funding support of the Institute for Global Environmental Strategies (IGES) through the Satoyama Development Mechanism (SDM) Project; and through the warm accommodation and active participation of Barangay Alitas, particularly AFA members, LGU of Infanta, and DENR-CENRO Real, Quezon during the conduct of field data collection.

\section{References}

Akter, S. (2015). Climate change hazards vulnerability and resilience capacity assessment for Char land women in Bangladesh. PhD Thesis, University of Dhaka, Bangladesh.

Ali, F., Ingirige, B., \& Abidin, N. (2018). Assembling and (re)assembling critical infrastructure resilience in Khulna City, Bangladesh. Procedia Engineering, 212, 832-839.

Abarquez, I., \& Murshed, Z. (2004). CBDRM field practitioners' handbook. Bangkok: Asian Disaster Preparedness Center (ADPC).

Center for Community Enterprise. (2000). The community resilience manual: A resource for rural recovery and renewal, The Center for Community Enterprise, British Columbia, Canada.

Chua, T. (1998). Lessons learned from practicing integrated coastal management in Southeast Asia. Ambio, 27, 599-610.

Camacho, L., Gevaña, D., Carandang, A., Camacho, S., Combalicer, E., Rebugio, L., \& Youn, Y. (2011). Tree biomass and carbon stock of a community-managed mangrove forest in Bohol, Philippines. Forest Science and Technology, 7(4), 161-167.

CAPRA. (2012). The important distinction between disaster and risk. Retrieved 14 March, 2020, from https://ecapra.org/documents/important-distinction-between-disaster-and-risk

Frankenberger, T., Mueller, M., Spangler, T., \& Alexander, S. (2013). Community resilience: Conceptual framework and measurement feed the future learning agenda. Rockville: Westat.

Garcia, K., Malabrigo, P., \& Gevaña, D. (2014). Philippines' mangrove ecosystem: Status, threats and conservation. In I. Faridah-Hanum, A. Latiff, K. R. Hakeem, \& M. Özturk (Eds.), Mangrove ecosystems of Asia: Status, challenges and management strategies (pp. 81-94). New York: Springer.

Gevaña, D., \& Im, S. (2016). Allometric models for Rhizophora stylosa Griff. in dense monoculture plantation in the Philippines. Malaysian Forester, 79(1 \& 2), 39-53.

Gevaña, D., Camacho, L., \& Pulhin, J. (2018). Conserving mangroves for their blue carbon: Insights and prospects for community-based mangrove management in Southeast Asia. In C. Makowski \& C. W. Finkl (Eds.), Threats to mangrove forests (Vol. 25, pp. 579-588). New York: Springer.

Gevaña, D., Pulhin, J., \& Tapia, M. (2019). Fostering climate change mitigation through a community-based approach: Carbon stock potential of community-managed mangroves in the Philippines. In R. R. Krishnamurthy, M. P. Jonathon, S. Srinivasalu, \& B. Glaeser (Eds.), Coastal management: Global challenges and innovations (pp. 271-282). London: Elsevier.

Honda, K., Nakamura, Y., Nakaoka, M., Uy, W., \& Fortes, M. (2013). Habitat use by fishes in coral reefs, seagrass beds and mangrove habitats in the Philippines. PLoS ONE, 8(8), 1-10. 
IPCC. (2012). Glossary of terms. In C. Field, V. Barros, T. Stocker, \& Q. Dahe (Eds.), Managing the risks of extreme events and disasters to advance climate change adaptation: A special report of the Intergovernmental Panel on Climate Change (pp. 555-564). Cambridge: Cambridge University Press.

Mallick, F. (2013). Habitat and infrastructures: A localized approach to resilience. In R. Shaw, F. Mallick, \& A. Islam (Eds.), Climate change adaptation actions in Bangladesh (pp. 331-340). Tokyo: Springer.

Menéndez, P., Losada, I., Torres-Ortega, S., Toimil, A., \& Beck, M. (2019). Assessing the effects of using high-quality data and high-resolution models in valuing flood protection services of mangroves. PLOS ONE, 14(8), 1-14.

Moles, O., Caimi, A., Islam, M., Hossain, T., \& Podder, R. (2014). From local building practices to vulnerability reduction: building resilience through existing resources, knowledge and knowhow. Procedia Economics and Finance, 18, 932-939.

Mustelin, J., \& Handmer J. (2013) Triggering transformation: Managing resilience or invoking real change? in Proceedings of transformation in a changing climate conference, University of Oslo, pp. 24-32.

Ostadtaghizadeh, A., Ardalan, A., Paton, D., Jabbari, H., \& Khankeh, H. R. (2015). Community disaster resilience: A systematic review on assessment models and tools. PLOS Currents Disasters, 7, 1-16.

Pal, U., Bahadur, A., McConnell, J., Vaze, P., Kumar, P., \& Acharya S. (2019). Unpacking transformation: A framework and insights from adaptation mainstreaming. ACT learning paper, action on climate today, Oxford Policy Management, UK.

Pfefferbaum, B., Pfefferbaum, R., \& Van Horn, R. (2014). Community resilience interventions: Participatory, assessment-based, action-oriented processes. American Behavioral Scientist, 59, 238-253.

PSA. (2018). Census of population 2018, Philippine Statistics Authority (PSA), Manila, Philippines.

Renaud, F., Sudmeier-Rieux, K., \& Estrella, M. (2013). The role of ecosystems in disaster risk reduction (p. 486). Tokyo: United Nations University Press.

Sameen, S. (2018). Process inclusive infrastructure: notions towards cyclone resilience in Bangladesh. Procedia Engineering, 212, 30-38.

Sharifi, A., \& Yamagata, Y. (2016). On the suitability of assessment tools for guiding communities towards disaster resilience. International Journal of Disaster Risk Reduction, 18, 115-124. https://doi.org/10.1016/j.ijdrr.2016.06.006.

Sharifi, A. (2016). A critical review of selected tools for assessing community resilience. Ecological Indicators, 69, 629-647.

Turnbull, M., Sterrett, C., \& Hilleboe, A. (2013). Toward resilience: A guide to disaster risk reduction and climate change adaptation. Warwickshire: Practical Action Publishing Ltd.

UNISDR. (2007). Hyogo framework for action 2005-2015: Building resilience of nations and communities to disasters. Geneva: United Nations International Strategy for Disaster Reduction.

UNU-IAS, Biodiversity International, IGES \& UNDP. (2014). Toolkit for the indicators of resilience in socio-ecological production landscapes and seascapes (SEPLS).

US Indian Ocean Tsunami Warning System Program. (2007). How resilient is your coastal community? A guide for evaluating coastal community resilience to Tsunamis and other coastal hazards. Bangkok: US Indian Ocean Tsunami Warning System Program supported by the United States Agency for International Development.

White, A. T., Christie, P., D’Agnes, H., Lowry, K., \& Milne, N. (2005). Designing ICM projects for sustainability: Lessons from the Philippines and Indonesia. Ocean and Coastal Management, $48,271-296$. 
The opinions expressed in this chapter are those of the author(s) and do not necessarily reflect the views of UNU-IAS, its Board of Directors, or the countries they represent.

Open Access This chapter is licenced under the terms of the Creative Commons Attribution 3.0 IGO Licence (https://creativecommons.org/licenses/by/3.0/igo/), which permits use, sharing, adaptation, distribution and reproduction in any medium or format, as long as you give appropriate credit to UNU-IAS, provide a link to the Creative Commons licence and indicate if changes were made.

The use of the UNU-IAS name and logo, shall be subject to a separate written licence agreement between UNU-IAS and the user and is not authorised as part of this CC BY 3.0 IGO licence. Note that the link provided above includes additional terms and conditions of the licence.

The images or other third party material in this chapter are included in the chapter's Creative Commons licence, unless indicated otherwise in a credit line to the material. If material is not included in the chapter's Creative Commons licence and your intended use is not permitted by statutory regulation, or exceeds the permitted use, you will need to obtain permission directly from the copyright holder. 